\title{
CENTELLA ASIATICA EXTRACT EFFECT ON POSTOPERATIVE WOUND HEALING
}

\author{
Elza Iskandar ${ }^{*}$, Theodorus ${ }^{2}$, Anang Tribowo ${ }^{1}$, Riani Erna ${ }^{1}$, Fatimah Syakirah ${ }^{3}$ \\ ${ }^{1}$ Department of Ophthalmology, Faculty of Medicine, Sriwijaya University, Palembang, Indonesia \\ 2Department of Pharmacology, Faculty of Medicine, Sriwijaya University, Palembang, Indonesia \\ ${ }^{3}$ Ophthalmology Residency Program, Faculty of Medicine, Sriwijaya University, Palembang, Indonesia \\ iskandarachmad1104@gmail.com
}

\begin{abstract}
Wound healing is a complex process that is divided into four phases, namely the hemostasis, inflammation, proliferation, and tissue remodeling phase. Centella asiatica is a widely used and very popular traditional plant in the field of health for a long time. Various in vitro and in vivo studies have proven the efficacy of Centella asiatica extract in the wound healing process. This literature review uses literature search methods from Pubmed, Science Direct, and Cochrane Library with keywords Centella asiatica, wound healing, surgery. This study aims to study the effects of Centella asiatica extract on postoperative wound healing.
\end{abstract}

\section{Keywords: Centella asiatica, Wound, Postoperative}

\section{INTRODUCTION}

Wounds are disorders or injuries to anatomical and physiological structures due to damage to organs such as the skin. This damage can extend to other tissues and structures such as subcutaneous tissue, muscles, tendons, nerves, blood vessels, and even bones. ${ }^{1}$

Wound healing is a complex process that is divided into four phases, namely hemostasis, inflammation, proliferation, and tissue remodeling. ${ }^{1-3}$ Wounds that are not treated properly will be at risk for pathological scarring that can interfere with esthetics, function, and affect the patient's psychology, including postoperative wounds. ${ }^{1,4-6}$

Until now, there are various methods in the treatment and prevention of scar formation, such as occlussive dressings, compression therapy, intralesional corticosteroid injection, radiation therapy, laser therapy, interferon therapy, topical silicone gels, and herbal extracts. Recently, various herbs have been proven to play an important role in the wound healing 


\section{IJIM}

process and scar tissue repair. A recent study on the herbal extract of Centella asiatica (CA) was conducted to improve the outcome of the wound healing process. ${ }^{7}$

CA is a plant known by various names. In India this plant is known as Indian pennywort, Jal Brahmi, Mandookaparni, or Gotu Kola. In Germany it is known as the Asiatischer wassernabel. In China it is known as Tungchian and Luei Gong Gen. In Indonesia, this plant is generally called Gotu Kola. CA grows in Asia, Madagascar, equatorial Africa, Central America, and tropical Oceania. There are several active components in CA, the main ones are asiaticoside, madecassoside, asiatic acid and madecassic acid. 8

In Asia, CA has been used for hundreds of years in the treatment of various conditions such as minor wounds, burns and hypertrophic scars, as well as an anti-inflammatory, antipyretic, diuretic, antibacterial, antiviral, drug for venous insufficiency, anticancer agent, antianxiety, and drugs to improve cognitive abilities. Previously, CA has also been used for epilepsy, leprosy, itching, and insect bites. ${ }^{8}$ This literature review aims to study the effect of Centella asiatica extract on postoperative wound healing.

\section{METHODS}

This is a literature review conducted by collecting English-language articles from January 1, 2020 to October 25, 2021 using search engine from Pubmed, Science Direct, and Cochrane Library with the keywords: "Centella asiatica", "wound healing", and "surgery". From the literature search, 134 articles were retrieved and then screened to obtain articles that matched the inclusion criteria. In addition, we also manually reviewed the bibliographies of included articles that met the inclusion criteria. Inclusion criteria were quantitative research with postoperative patient subjects who were given Centella asiatica. Irrelevant and similar articles were excluded after a review of the titles and abstracts.

English language articles from January $1^{\text {st }}, 2000$ to October $25^{\text {th }}, 2021$ were retrieved using online search engines (Pubmed, Science Direct, Cochrane Library) with keywords: Centella asiatica, wound healing, surgery

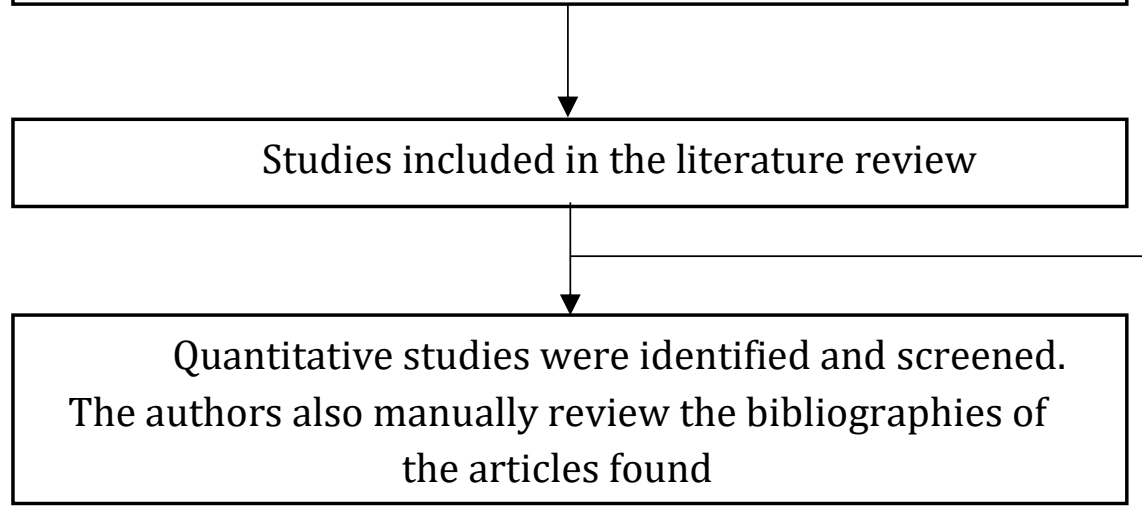

Figure 1. Flowchart for the study selection process 


\section{DISCUSSION}

\section{Wound Healing}

Wound healing is a complex process that results in restoration of tissue integrity. This process is divided into four phases, namely hemostasis, inflammation, proliferation, and tissue remodeling. ${ }^{1-3}$

The hemostasis phase is a process that occurs immediately as an initial response to injury. This response involves the role of platelets and the coagulation cascade to prevent extravasation and establish hemostasis. The inflammatory phase in wound healing aims to prevent infection. This process is traversed through various chemical signaling mechanisms including the complement cascade, interleukin activation and signaling transforming growth factor beta (TGF- $\beta$ ) resulting in chemotaxis. ${ }^{3,9,10}$ Cells that play a role in this phase such as neutrophils, macrophages, lymphocytes, fibroblasts, and endothelial cells. The inflammatory phase of wound healing will last as long as bacteria and debris remain in the wound. The proliferative phase begins when the wound stimulus has stopped, hemostasis has occurred, the inflammatory response has stabilized and there is no more debris, consisting of the process of angiogenesis, granulation tissue formation, collagen deposition, epithelialization and wound retraction at the same time. The final phase of wound healing process is the remodeling phase that causes normal epithelial development and maturation of scar tissue. 3,9

One of the complications of surgical wounds is pathological scarring, either in the form of hypertrophic scars or keloids. This complication can affect the patient's function, cosmetics, and psychology. ${ }^{3}$
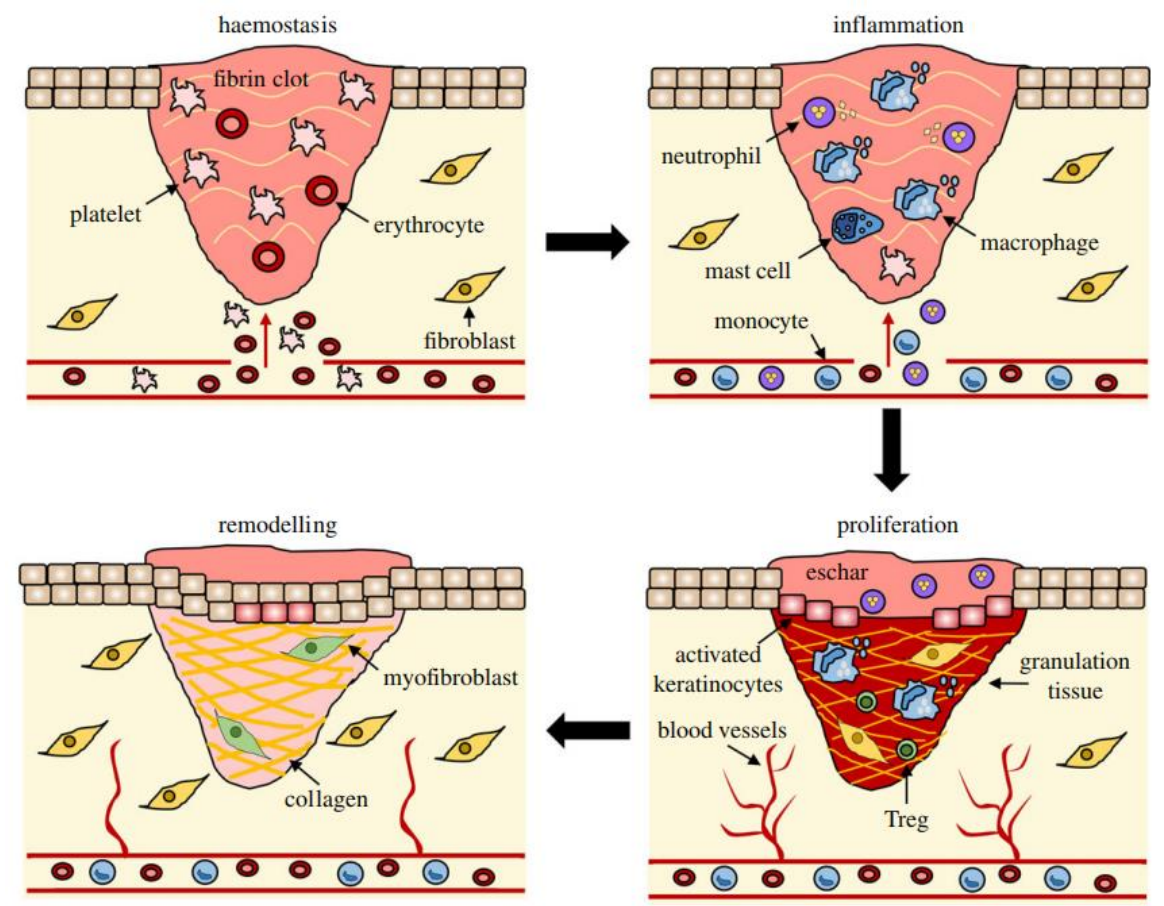

Figure 2. Wound healing process ${ }^{2}$ 


\section{IJIM}

\section{Centella asiatica}

Centella asiatica or Gotu Kola grows in tropical and subtropical areas.8,11 It measures up to $15 \mathrm{~cm}$, with 1-3 leaves measuring 2- $6 \mathrm{~cm}$ long and 1.5-5 cm wide on each stem. The flowers are white to purple or pink. ${ }^{12}$ Taxonomically, Centella belongs to the family Apicaeae (Umbralliferae) and has 20 species. $^{13}$

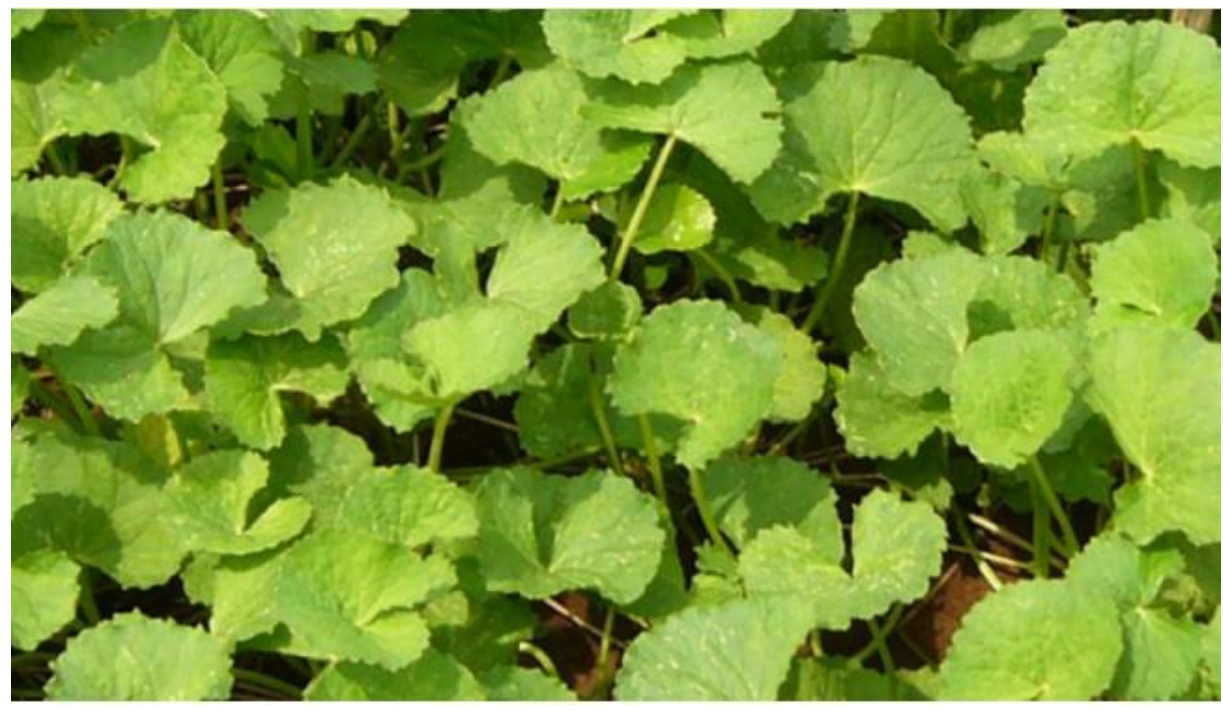

Figure 3. Centella asiatica ${ }^{14}$

The main chemical constituents of CA are triterpenes, including triterpenic acid and phenolic glycosides respectively, such as asicatic acid, asiaticoside, madecassic acid, madecassoside, brahmic acid, brahmoside, brahminoside, thankuniside, isothankuniside, centelloside, madasiatic acid, centic acid, cenellic acid, betulinic acid, and indocentic acid. ${ }^{15}$ Of these various components, asiatic acid, asiaticoside, madecassic acid, and madecassoside are the most important bioactive components with the most important pharmacological effects. ${ }^{13,16}$

CA has long been used in the treatment of wounds, burns, various skin conditions, neurological and gastrointestinal disorders in traditional Chinese medicine, Ayurvedic medicine, and traditional Southeast Asian medicine. This plant is included in the list of pharmacopoeia drugs in many countries, such as Germany, India, and the Republic of China. In China, the leaves of CA are used to treat leukorea and fever while in India this plant is used to treat various diseases such as asthma, bronchitis, elephantiasis, kidney disorders, gastric disorders, leprosy, leukorea, skin diseases and urethritis. In India and Pakistan, the crushed leaves are topically applied to treat wounds or skin ulcers. In Thailand, CA is included in the Thai Fundamental Public Health Drug List as a wound healing agent in extract cream preparations. In Malaysia, although this plant is usually used as vegetables for food (salad), it is also said to have benefits in improving memory and treating mental weakness, anxiety and eczema. ${ }^{11,13}$ 
Extracts from CA have been used by the people of Java and the Malay Peninsula for many years, both as a topical and internal agent, for the treatment of wound healing and cognitive impairment in mental retardation disorders. Further experimental researchs on the biological content of CA extracts showed that CA has anti-oxidant activity and antiproliferative effect. Many scientific data have supported the efficacy of CA in the treatment of wounds and burns, as well as in the prevention of hypertrophic scars. ${ }^{11,13}$

\section{Mechanism of Centella asiatica Extract in Wound Healing}

CA extract has been used traditionally for wound healing and various studies have been carried out to support this statement. ${ }^{13,17}$ The mechanism of action of Centella in relation to wound healing is by increasing fibroblast proliferation, increasing collagen and mucopolysaccharide acid synthesis, increasing intracellular fibronectin and miotic activity, which then increases the tensile strength of the newly formed skin, and inhibits the inflammatory phase. 18

Somboonwong et al. examined the effect of topical application of four different CA extracts on partial thickness burns in rats. All extracts increased the healing rate but at different time points with comparable wound healing results on day $14 .^{11}$

CA and its components in wound suppress inflammation by inhibiting prostaglandins, kinins, histamine, proinflammatory cytokines, and proinflammatory enzymes, antioxidant activity and stabilizing lysosomal enzymes. Terpene glycosides and beta-sitosterol are the main compounds of CA which are responsible for stimulating wound angiogenesis. Shukla et al. demonstrated that asiaticoside could improve wound healing by stimulating angiogenesis. The study of Coldren et al. demonstrated that titrated extract of Centella asiatica induces the formation of proangiogenic factors and decreases the expression of anti-angiogenic thrombospondins. ${ }^{11}$

CA plays a positive role in extracellular matrix formation and wound remodeling. A large number of in vivo experiments have shown an increase in the synthesis of collagen, hydroxyproline or glycosaminoglycans or an increase in wound tensile strength after administration of the CA extract. Similar results were obtained for delayed wound healing, such as those caused by dexamethasone and diabetes. In an in vitro study, it was reported that asiaticoside and madecasssoside can stimulate the synthesis of type I collagen which replaces type III collagen in the remodeling phase. ${ }^{11}$

In several experimental studies, CA and its constituents showed a better wound epithelialization effect. Asiaticoside affects the epithelialization process by stimulating the cells of the Malpighian layer and increasing the migration and initial adhesion of keratinocytes in the epidermal layer of the skin in an in vitro wound healing model. Meanwhile, madecassoside has been reported to increase the re-epithelialization of burns in rats. ${ }^{11}$

CA also plays a role in the prevention and reduction of hypertrophic scarring. From the research of Widgerow et al. It is known that CA promotes scar tissue maturation and inhibits inflammation. As for the hypertrophic scars and keloids that have formed, recent research has 
focused on identifying the underlying components, particularly those involving inhibition of the TGF- $\beta /$ Smad pathway. ${ }^{11}$

Preclinical studies of various formulations of CA extract applied to open wounds in mice resulted in increased cell proliferation and collagen synthesis in the wound area. Wounds which was given CA extract experienced a faster epithelialization process and the speed of wound contraction was higher when compared to untreated wounds. ${ }^{16,18}$ Asiaticoside also has wound healing activity by increasing collagen synthesis, angiogenesis, and has been shown to increase skin binding capacity and inhibit the inflammation process that can stimulate the formation of hypertrophic scars and improve capillary permeability. Shukla et al. who examined the antioxidant effect of CA extract on animals concluded that asiaticoside has an antioxidant effect where antioxidants have a role in the wound healing process, especially in the early phase. In a study conducted in guinea pigs, topical application of $0.2 \%$ asiaticoside resulted in an increase in hydroxyproline, an increase in binding capacity, an increase in collagen content and epithelialization. In streptozocin-induced diabetic rats, topical application of $0.4 \%$ asiaticoside also increased hydroxyproline, skin adhesion, collagen content and epithelialization. ${ }^{15,19} \mathrm{CA}$ extract increased cellular proliferation and collagen synthesis in the wound area as evidenced by increased DNA, protein and collagen content of granulation tissue. Wounds treated with Centella extract experienced faster epithelialization and a higher speed of wound contraction compared to the control group. 8,20

\section{Effects of Centella asiatica Extract on Postoperative Wound Healing}

According to a randomized double-blind study conducted by Jeenwithsuk et al, the use of CA cream showed better pigmentation and total Vancouver Scar Scale (VSS) scores than placebo in postoperative wounds of split-thickness skin graft donors, so CA cream can be the product of choice to prevent formation of hypertrophic scar tissue. ${ }^{7}$ These results are also similar to a 2013 study by Chuangsuwanich et al that investigated the efficacy of a combination herbal extract gel (Cybele ${ }^{\circledR}$ scagel) containing Allium cepa, Centella asiatica, Aloe vera, Paper mulberry, nanohydroxyprolisilane $\mathrm{CN}$ in split-thickness skin graft donor patients in reducing scar tissue formation. From this study, it was found that the total VSS score was significantly lower in the combined herbal extract group after 4 weeks of application and a significantly higher level of patient satisfaction in the combined herbal extract group after the 12th week evaluation. ${ }^{21}$

The study by Gao et al (2019) in 90 post-epicanthoplasty patients obtained a lower POSAS (Patient Observer Scar Assessment Scale) score in the asiaticoside cream treated group than the non treated group. Patient satisfaction in the asiaticoside group was also higher than in the no-therapy group at 6-month follow-up. Thus, from this study it was concluded that asiaticoside cream could provide a better clinical effect on scar tissue formation after epicanthoplasty. ${ }^{22}$

In a study conducted by Pratasmi in 60 post partum patients with episiotomy wounds treated with CA, there was a significant effect on the healing process of episiotomy wounds. ${ }^{23}$ 
A 2018 study by Cotellese et al in patients with post abdominal or knee surgery showed that administration of CA extract capsules (Centellicum ${ }^{\circledR}$ ) for 2-6 weeks compared to the standard therapy group showed good tolerability and no side effects, a significantly better scar regularity tissue when being assessed by ultrasound, significantly more homogeneous scar tissue than the control group, and good drug adherences. ${ }^{17}$

A study conducted by Chiaretti et al in 2020 on the use of CA versus flavonoids and standard therapy in patients with hemorrhoidal disease found that administration of CA as a phlebotonic agent showed a significant beneficial effect, both in patients with conservative and surgical therapy. Of the 31 post-hemorrhoidectomy patients, it was found that the CA group showed a better trend in the mean time required to stop bleeding than the control group. Meanwhile, 34 patients with hemorrhoidal thrombosis after incision and drainage showed a faster decrease in Visual Acuity Score (VAS) than the control group. In addition, the wound healing time was faster ( 2 weeks compared to the control group which took 4 weeks) although this result was not statistically significant. ${ }^{24}$

In a study conducted on as many as 30 post-laser resurfacing patients, the patients who used CA gel showed a significantly lower erythema index. In addition, there was an increase in improvement of skin erythema and overall wound appearance on the $2 \mathrm{nd}$, 4 th, and 7 th days of gel use. The researchers then concluded that CA could be an option for therapy in post-laser resurfacing patients to improve wound appearance. ${ }^{25}$ Another study by Kang et al in postlaser resurfacing patients comparing CA extract and purified water resulted in significant differences in term of hyperpigmentation at 6 months post-laser and significant differences in moisture at one and four hours post-laser. The study concluded that CA extract provides a moist wound environment thus inducing faster wound healing and preventing postinflammatory hyperpigmentation after ablative fractional $\mathrm{CO}_{2}$ laser resurfacing so that $\mathrm{CA}$ extract is a post-laser therapy modality that can provide satisfactory results without postlaser complications. ${ }^{26}$

Surakunprapha et al (2020) conducted a randomized double-blind study in poststernotomy patients divided into two groups: group 1 (a combination of topical silicon gel and herbal extract) and group 2 (topical silicone gel only). Herbal extracts consist of Centella asiatica, Allium cepa, Aloe vera, and Paper mulberry. The results showed total VSS scores were significantly better in group 1 with significantly improved pigmentation and vascularity scores in the 3rd and 6th months. From this study researchers concluded that post sternotomy scar has better vascularity and pigmentation when treated with a combination of topical silicon gel and herbal extracts. ${ }^{27}$ The study was in line with a 2011 study by Jeenwithsuk in post-median sternotomy patients divided into 2 groups which were treated with Cybele® scagel (group 1) or placebo (group 2) for 12 weeks resulting in significantly lower pain and itching score results in group 1, significant differences in pigmentation between groups, and all VSS parameters in group 1 showed improvements primarily in terms of pigmentation. This gel was concluded to be safe and effective for preventing hypertrophic scarring after median sternotomy. ${ }^{28}$ The results of a 2019 study that also compared the administration of a 
combination of silicone gel and herbal extracts (Allium cepa, Centella asiatica, Aloe vera, Paper mulbery) with placebo in post-sternotomy patients provides similar results. ${ }^{29}$

A 2014 study by Chuangsuwanich and Jongjamfa examined the efficacy of combination herbal extract gels (Allium cepa, Centella asiatica, Aloe vera, Phyllanthus emblica, and Tamarindus indica) against the prevention of postoperative scar tissue formation. Of the 17 patients with bilateral symmetrical surgery scars, the Patient Scar Assessment Scale (color, stiffness, thickness, iregularity, and overall score) was significantly lower at 12 weeks after herbal extracts use. The Observer Scar Assessment Scale score of vascularity, relief, and pliability was also significantly lower at 8 weeks post-therapy. From this study it was concluded that the combination herbal extracts gel can be effective in the prevention of postoperative scarring. ${ }^{30}$

A comparative study comparing the efficacy of Centelline ${ }^{\circledR}$ (Bulbinella frutecens, Centella asiatica, and oleuropein) and white petrolatum in patients who had a shave biopsy showed that Centelline ${ }^{\circledR}$ showed faster scar tissue repair than petrolatum. In the first week, Centelline ${ }^{\circledR}$ showed $50 \%$ improvement in overall wound appearance, better efficacy in vascularity, thickness, and wound relief, as well as faster reduction of symptoms such as stinging/burning and itching. In the $2^{\text {nd }}$ week the Centelline ${ }^{\circledR}$ group continued to show improvement in terms of vascularity and pigmentation. CA plays a role in triggering collagen maturation and conversion and reduces tension-related collagen formation. ${ }^{31}$

Research by Romo et al on the effectiveness of CA cream and Pinus Sylvesteris (Cicatrix ${ }^{\circledR}$ ) in patients with postoperative scars showed that $46.7 \%$ of scar tissue was smallerby more than $50 \%, 72 \%$ of scar tissue improved in terms of color, and $98,7 \%$ of patients with postoperative scars respond well to therapy. Thus CA and Pinus Sylvesteris are excellent alternative therapies for postoperative scars. ${ }^{32}$

\section{CONCLUSION}

Effects of CA extract on wound healing include inhibiting the inflammatory process and promoting wound proliferation and remodeling. CA extract has been shown to have a good effect on postoperative wound healing, especially in the formation of scar tissue. 


\section{REFERENCES}

1. Okur ME, Karantas ID, Şenyiğit Z, Üstündağ Okur N, Siafaka PI. Recent trends on wound management: New therapeutic choices based on polymeric carriers. Asian Journal of Pharmaceutical Sciences. 2020 Nov 1;15(6):661-84.

2. Wilkinson HN, Hardman MJ. Wound healing: cellular mechanisms and pathological outcomes: Cellular Mechanisms of Wound Repair. Open Biology. 2020 Sep 1;10(9).

3. Harper D, Young A, McNaught CE. The physiology of wound healing. Surgery (United Kingdom). 2014 Jul 24;32(9):445-50.

4. Vercelli S, Ferriero G, Sartorio F, Stissi V, Franchignoni F. How to assess postsurgical scars: A review of outcome measures. Disability and Rehabilitation. 2003 Jan 1;25(31):2055-63.

5. Hintschich C. Periokuläre plastische chirurgie. Deutsches Arzteblatt. 2010 Mar 5;107(9):141-6.

6. Oestreicher J, Mehta S. Complications of Blepharoplasty: Prevention and Management. Plastic Surgery International. 2012;2012:1-10.

7. Jenwitheesuk K, Rojsanga P, Chowchuen B, Surakunprapha P. A prospective randomized, controlled, double-blind trial of the efficacy using centella cream for scar improvement. Evidence-based Complementary and Alternative Medicine. 2018;2018.

8. Bylka W, Znajdek-Awizeń P, Studzińska-Sroka E, Brzezińska M. Centella asiatica in cosmetology. Postepy Dermatologii i Alergologii. 2013;30(1):46-9.

9. Tsioufis C, Bafakis I, Kasiakogias A, Stefanadis C. The role of matrix metalloproteinases in diabetes mellitus. Current Topics in Medicinal Chemistry. 2012;12(10):1159-65.

10. Berman B, Maderal A, Raphael B. Keloids and hypertrophic scars: Pathophysiology, classification, and treatment. Dermatologic Surgery. 2016;2017(43):3-18.

11. Soomboonwong J. Chinese Herbs and Herbal Medicine. Duke BL, editor. Chinese Herbs and Herbal Medicine. New York: Nova Science Publisher, Inc.; 2015. 48-62.

12. Singh S, Gautam A, Sharma A, Batra A. CENTELLA ASIATICA (L.): A PLANT WITH IMMENSE MEDICINAL POTENTIAL BUT THREATENED. International Journal of Pharmaceutical Sciences Review and Research. 2010;4(2):9-17.

13. Calapai Gioacchino. Assessment report on Centella asiatica (L.) Urban, herba [Internet]. London; 2010 Nov. Available from: www.ema.europa.eu

14. Sutardi S. Kandungan Bahan Aktif Tanaman Pegagan dan Khasiatnya untuk Meningkatkan Sistem Imun Tubuh. Jurnal Penelitian dan Pengembangan Pertanian. 2017 Jan 23;35(3):121.

15. Randriamampionona D, Diallo B, Rakotoniriana F, Rabemanantsoa C, Cheuk K, Corbisier AM, et al. Comparative analysis of active constituents in Centella asiatica samples from Madagascar: Application for ex situ conservation and clonal propagation. Fitoterapia. 2007 Dec;78(7-8):482-9.

16. Wu F, Bian D, Xia Y, Gong Z, Tan Q, Chen J, et al. Identification of major active ingredients responsible for burn wound healing of Centella asiatica herbs. Evidence-based Complementary and Alternative Medicine. 2012;2012.

17. Cotellese R, Hu S, Belcaro G, Ledda A, Feragalli B, Dugall M, et al. Centella asiatica (Centellicum ${ }^{\circledR}$ ) facilitates the regular healing of surgical scars in subjects at high risk of keloids. Minerva chirurgica. 2018 Nov;73:151-6.

18. Ago M, Adifa D N,. Benefits of Gotu Kola Leaf in Responding to Prevent the Form of Keloid in The Wound. Indonesian Journal of Global Health Research. 2020 Feb 1;2(1):23-8. 
19. Abdul Hamid A, Md Shah Z, Muse R, Mohamed S. Characterisation of antioxidative activities of various extracts of Centella asiatica (L) Urban. Food Chemistry. 2002;465-9.

20. Tang B, Zhu B, Liang Y, Bi L, Hu Z, Chen B, et al. Asiaticoside suppresses collagen expression and TGF- $\beta /$ Smad signaling through inducing Smad 7 and inhibiting TGF- $\beta$ RI and TGF- $\beta$ RII in keloid fibroblasts. Archives of Dermatological Research. 2011 Oct;303(8):56372.

21. Chuangsuwanich A, Arunakul S, Kamnerdnakta S. The efficacy of combined herbal extracts gel in reducing scar development at a split-thickness skin graft donor site. Aesthetic Plastic Surgery. 2013 Aug;37(4):770-7.

22. Gao X, Lin J, Sun L. Clinical effects of Dermatix Ultra silica gel and asiaticoside cream on hyperplastic scar tissue in patients after epicanthoplasty. Chinese Journal of Medical Aesthetics and Cosmetology. 2019 Dec 15;25:508-11.

23. Pratami E, Isfentiani D. Centella asiatica EXTRACT REDUCES PAIN AND ENHANCES EPISIOTOMY WOUND HEALING. In: International Conference On Health Polytechnic Surabaya. Surabaya; 2016. p. 243-8.

24. Chiaretti M, Fegatelli DA, Pappalardo G, Venti MDS, Chiaretti AI. Comparison of Centella with Flavonoids for Treatment of Symptoms in Hemorrhoidal Disease and After Surgical Intervention: A Randomized Clinical Trial. Scientific Reports. 2020 Dec 1;10(1).

25. Damkerngsuntorn W, Rerknimitr P, Panchaprateep R, Tangkijngamvong N, Kumtornrut C, Kerr SJ, et al. The Effects of a Standardized Extract of Centella asiatica on Postlaser Resurfacing Wound Healing on the Face: A Split-Face, Double-Blind, Randomized, PlaceboControlled Trial. Journal of Alternative and Complementary Medicine. 2020 Jun 1;26(6):529-36.

26. Kang MS, Park KC, Nam SM. A split-face study of moisturizer containing Centella asiatica extract after ablative fractional carbon dioxide laser resurfacing. Archives of Aesthetic Plastic Surgery. 2021 Apr 30;27(2):56-60.

27. Surakunprapha P, Winaikosol K, Chowchuen B, Jenwitheesuk K, Jenwitheesuk K. Adding Herbal Extracts to Silicone Gel on Post-Sternotomy Scar: A Prospective Randomised Double-Blind Study. Journal of Wound Care. 2020;29:36-42.

28. Jenwitheesuk K, Surakunprapha P, Jenwitheesuk K, Kuptarnond C, Prathanee S, Intanoo W. Role of silicone derivative plus onion extract gel in presternal hypertrophic scar protection: A prospective randomized, double blinded, controlled trial. International Wound Journal. 2012 Aug;9(4):397-402.

29. Surakunprapha P, Winaikosol K, Chowchuen B, Punyavong P, Jenwitheesuk K, Jenwitheesuk K. A Prospective Randomized Double-blind study of silicone gel plus Herbal Extracts Versus Placebo in Pre-sternal hypertrophic scar prevention and amelioration. Heliyon. 2020 May 1;6(5).

30. Chuangsuwanich A, Jongjamfa K. The Efficacy of Combined Herbal Extracts Gel Preparation in the Prevention of Postsurgical Hypertrophic Scar Formation. Dermatology and Therapy. 2014 Dec 1;4(2).

31. Kircik LH. Comparative Study of the Efficacy and Tolerability of a Unique Topical Scar Product vs White Petrolatum Following Shave Biopsies. J Drugs Dermatol. 2013;12(1):8690.

32. Romo EM, Fundora FP, Albajes CR, Esteris López L, Hana Z. The effectiveness of cream with Centella Asiatica and Pinus Sylvestris to treat scars and burns. Clinical trail. Dermatologia Kliniczna. 2012;14(2):105-10. 